Published in final edited form as:

Exp Clin Endocrinol Diabetes. 2016 March ; 124(3): 140-147. doi:10.1055/s-0035-1569374.

\title{
Factors Associated with Higher Pro-Inflammatory Tumor Necrosis Factor-a Levels in Young Women with Type 1 Diabetes
}

\author{
Kirstie K. Danielson ${ }^{a, b}$, Rebecca S. Monson ${ }^{a}$, and Tamara J. LeCaire ${ }^{c}$ \\ aDivision of Transplant Surgery, College of Medicine, University of Illinois at Chicago

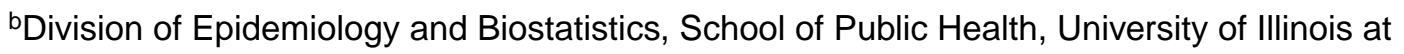 \\ Chicago \\ 'Department of Population Health Sciences, University of Wisconsin-Madison
}

\section{Abstract}

\begin{abstract}
Aims-While cytokines play a role in the etiology of type 1 diabetes, cytokines later in the disease are less understood. We therefore investigated associations of pro-inflammatory tumor necrosis factor-a levels measured at prolonged disease duration with C-peptide at diagnosis, longterm glycemic control, diabetes duration, clinical factors, and health behaviors.
\end{abstract}

\begin{abstract}
Methods-Data and blood were collected during an ancillary study to the longitudinal Wisconsin Diabetes Registry, a population-based cohort followed since diagnosis of type 1 diabetes. The ancillary study was conducted at 13-18 years diabetes duration, and enrolled premenopausal women age $18-45$ years $(n=87)$.
\end{abstract}

\begin{abstract}
Results-Higher tumor necrosis factor-a levels at 13-18 years diabetes duration were independently associated with longer duration $(\mathrm{p}=0.0004)$ and worse current renal function $(\mathrm{p}=0.02)$. Additionally, diabetes duration modified both of the positive associations of tumor necrosis factor-a levels (both interactions $\mathrm{p} ₫$ ).01) with mean glycemic control during the previous 10 years (significant only in women with longer durations) and current daily caffeine intake (significant only in women with shorter durations). In women with C-peptide measured at diagnosis $(\mathrm{n}=50)$, higher tumor necrosis factor- $\alpha$ levels at 13-18 years duration were associated with lower C-peptide ( $\mathrm{p}=0.01$ ), independent of glycemic control during the previous 10 years.
\end{abstract}

\begin{abstract}
Conclusions-Lower residual C-peptide at diagnosis and poor long-term glycemic control independently predicted higher pro-inflammatory tumor necrosis factor-a levels years later. The novel relationship with C-peptide needs confirmation in a larger cohort. Given the association between tumor necrosis factor- $\alpha$ and diabetes complications, further longitudinal studies may help clarify the potentially complex associations between glycemic control, inflammatory cytokines, and complications.
\end{abstract}

\footnotetext{
Address for Correspondence: Kirstie K. Danielson, Ph.D. 840 S. Wood Street, Rm. 520 CSB (MC 958), Chicago, IL 60612-4325, Phone: 1-312-996-6820, Fax: 1-312-413-7961, kdaniel@uic.edu.

The original publication is available at Experimental and Clinical Endocrinology \& Diabetes: https://www.thieme-connect.com/DOI/ DOI?10.1055/s-0035-1569374
} 


\section{Keywords}

diabetes type 1; C-peptide; TNF-a; young women

With the incidence of type 1 diabetes among children under 14 years old rising approximately $3 \%$ annually worldwide, the burden of this disease will only continue to increase [1]. In the United States (US), the age-standardized annual incidence in nonHispanic white children $\leq 4$ years old is 27.5 per 100,000/year [2], one of the higher rates. In 2009, the overall prevalence of type 1 diabetes in US youth $<20$ years old was approximately 1.9 cases per 1000, with 2.6 cases per 1000 in non-Hispanic whites [3]. Type 1 diabetes occurs as a result of T-cell mediated autoimmune destruction of the $\beta$-cells of the pancreas. T-cells specific for auto-antigens in the b-cells escape immune regulation, are activated, and expand clonally, producing immune and inflammatory cascades that result in $\beta$-cell damage/death [4]. Cytokines, including tumor necrosis factor-a (TNF- $\alpha$ ) and interferon- $\gamma(\mathrm{IFN}-\gamma)$ [5] among others, have been found to play a role in the pathogenesis of type 1 diabetes.

Studies of cytokines after diagnosis of type 1 diabetes have varied in the cytokines studied, study design, and the duration of disease and follow-up. Findings concerning the relationship of cytokines with duration of type 1 diabetes have varied [6-10]. For example, TNF-a was negatively correlated with disease durations ranging from diagnosis to $\sim 3$ years [6]; whereas IFN- $\gamma$ was positively correlated with durations from 1 to 12 months [7]. These data suggest that cytokine levels may be dynamic during the course of the disease. Cytokines may also be involved in other aspects of type 1 diabetes after diagnosis. Several crosssectional studies evaluating the association of cytokines and complications in type 1 diabetes found that IL-6 and/or TNF-a were positively associated with micro- $[11,12]$ and macrovascular complications [11]. For example, higher levels of TNF-a were associated with increasing levels of vascular cell adhesion molecule-1 (VCAM-1) [13], a marker of endothelial dysfunction, and urinary albumin excretion [11]; and higher levels were also found in patients with, compared to those without, clinically apparent cardiovascular disease [11].

Cytokines may be influenced by the disease process itself. Cross-sectional studies that considered the relationship between cytokines and C-peptide levels mostly found no association $[6,7,10,14]$, while one found a positive association between an increase in Cpeptide secretion in the first six months after diagnosis and IL-6 levels at 12 months [14]. With regard to glycemic control, a study in individuals with impaired glucose tolerance found that clamp-induced hyperglycemia can acutely increase levels of pro-inflammatory cytokines [15]. Observational cross-sectional studies in type 1 diabetes have shown both a positive [16] and no association [6,10,17-19] between cytokines and hemoglobin A1c (HbA1c).

As many of the studies begin at diabetes diagnosis and have limited follow-up, it is unknown how type 1 diabetes and cytokines interact during the chronic phase of the disease. As TNFa may be involved in both the onset, and later complications, we chose to focus on its relationship with type 1 diabetes in particular. We therefore sought to prospectively evaluate 
the association of C-peptide at diagnosis, long-term glycemic control, and diabetes duration with TNF-a levels in young women from a population-based Registry of individuals with type 1 diabetes followed from diagnosis through 13-18 years duration. In addition, we determined the cross-sectional associations of potentially modifiable health behaviors (e.g., dietary patterns, physical activity, smoking and alcohol use), as well as clinical factors (e.g., diabetes management, renal function, and medical history) with TNF-a levels at 13-18 years duration in these young women to inform continued advancement of patient education and diabetes care. We hypothesized that higher levels of pro-inflammatory TNF-a would be associated with longer duration of type 1 diabetes, disease associated complications, and other poor health behaviors, including inadequate glycemic control.

\section{Materials and Methods}

\section{Population and sample}

The Wisconsin Diabetes Registry Study (WDRS) is a longitudinal study of glycemic control and micro- and macrovascular complications in a population-based cohort of incident cases with type 1 diabetes. Briefly, new cases $\mathfrak{3 0}$ years of age, diagnosed between May 1987 and April 1992, and living in 28 contiguous counties in Wisconsin were originally enrolled ( $\mathrm{n}=597$, including 288 females; Figure 1) [20]. The Registry's use of clinical criteria to define type 1 diabetes, including symptoms of polyuria and polydipsia, along with the initiation of exogenous insulin therapy [21], was in accord with the American Diabetes Association's guidelines for diagnosis at that time [22], and accurate overall as only seven (including four females) of 597 participants initially enrolled were ever able to discontinue exogenous insulin.

In January 2005, 191 participants met the preliminary enrollment criteria for a smaller ancillary study of bone health of premenopausal women with type 1 diabetes [23]: continued participation in WDRS, female, 18-45 years of age, and living in Wisconsin. At the end of the recruitment phase in December 2005, 89 eligible women with type 1 diabetes had participated in this ancillary study (Figure 1; enrollment details have been previously published [23]). Study approval was obtained from the Institutional Review Boards at the University of Wisconsin-Madison and the University of Illinois at Chicago, and participants provided written informed consent at enrollment and at all subsequent study visits.

\section{Data collection and variables}

Blood sample collection during ancillary study-As part of the ancillary study visit in 2005, blood samples were obtained by venipuncture for determination of TNF-a levels and current glycemic control (HbA1c). Visits were scheduled during days 20-24 of the participant's menstrual cycle (luteal phase) as levels of some cytokines vary during menses [24]. The blood was drawn without regard to fasting, time of day, or season, however given the known variability of cytokine levels [25], these characteristics of the blood draw were noted to be examined as precision adjustments during multivariable statistical modeling. An aliquot of whole blood was taken for HbA1c testing. The blood samples were then centrifuged, and the serum separated. A serum pregnancy test was conducted, with all results being negative. Aliquots of serum for future biomarker measurement were then frozen at 
$-80^{\circ} \mathrm{C}$ and archived for long-term storage until being shipped to laboratories for analysis as described below.

Tumor necrosis factor-a levels from ancillary study (dependent variable)—For the current analysis, TNF-a levels were measured in 2011 in the archived serum frozen at $-80^{\circ} \mathrm{C}$, using the high-sensitivity Milliplex Human Cytokine/Chemokine Panel I (Millipore Corp., Billerica, MA) with the Luminex system at University of Illinois at Chicago (Chicago, IL). The intra-assay coefficient of variation (CV) was 3.5\%, and the inter-assay $\mathrm{CV}$ was $3.8 \%$. Levels of TNF-a were not able to be determined in two participants due to insufficient archived serum, for a final TNF-a sample size of 87 women (Figure 1).

\section{Independent variables}

Health behaviors and clinical factors collected during ancillary study: A standard stadiometer height rod and calibrated Healthometer (Bridgeview, IL) physician beam scale were used to measure height and weight, respectively. Body mass index (BMI) was calculated as weight (kilograms) / height (meters) ${ }^{2}$. The average of two measurements of waist and hip circumferences were used to calculate the waist-to-hip ratio. A selfadministered questionnaire was used to collect additional data including: education and family income; health behaviors such as weight change within the last year, smoking history and sleep habits; diet as measured by a food frequency questionnaire, including daily consumption of calcium, vitamin D, alcohol, and caffeine, quantified as units (e.g., grams or international units) per day [26]; medical history such as medications for blood pressure, hypothyroidism, or proteinuria; reproductive history including age at menarche, pregnancies and duration of breastfeeding, if applicable. An examiner-administered questionnaire was employed to collect data on hormonal contraceptive use. The participants also completed the Five-City Project physical activity assessment [27] with the examiner calculating energy expenditure from physical activity (quantified as kilocalories per kilogram weight per day, and as hours per week). Two forms of vitamin $\mathrm{D}\left(25 \mathrm{OHD}_{3}\right.$, the major circulating metabolite, and $1,25(\mathrm{OH})_{2} \mathrm{D}_{3}$ ) were measured in serum with radioimmunoassay by Fairview Diagnostic Labs (Minneapolis, MN). The intra- and inter-assay CVs were $\leq 3 \%$ for $1,25(\mathrm{OH})_{2} \mathrm{D}_{3}$ and $\triangleleft 5 \%$ for $25 \mathrm{OHD}_{3}$.

\section{Type 1 diabetes characteristics}

Data collected during ancillary study: A self-administered questionnaire collected information on the average number of blood glucose checks performed per day, insulin dose (analyzed as units of insulin per kilogram weight per day), and current insulin pump use. A fingerstick blood glucose level was performed, to rule out hypoglycemia, or unsuspected hyperglycemia, prior to blood being drawn. None of the women reported symptoms of uncontrolled blood sugars during the blood draw.

As a measure of glucose control during the previous six to eight weeks, HbAlc level was determined. Whole blood samples were analyzed within seven days of collection by Fairview Diagnostic Labs (Minneapolis, MN). Automated high performance liquid chromatography was used following the Diabetes Control and Complications Trial (DCCT) reference method [28]. The non-diabetic levels for this assay range between 4.3-6.0\% (23-42 
$\mathrm{mmol} / \mathrm{mol}$ ). The inter-assay CV reported by the lab was $2.5-3.3 \%$ while the intra-assay CV from blind split-samples was $0.6 \%$.

As a measure of renal function, Cystatin-C was measured in 2011 in the archived serum frozen at $-80^{\circ} \mathrm{C}$ using the Milliplex Human Kidney Toxicity Panel 2 kit (Millipore Corp., St. Charles, MO) with the Luminex system at University of Illinois at Chicago (Chicago, IL). Cystatin- $\mathrm{C}$ was not able to be determined in two participants due to insufficient archived serum, and one extreme Cystatin-C outlier in the current analysis was excluded. The interand intra-assay CVs were $₫ \%$. Estimated glomerular filtration rate (eGFR) was calculated using the CKD-EPI Cystatin-C equation adjusted for age, sex, and race: $\mathrm{eGFR}=127.7 \times$ $(\text { Cystatin-C }(\mathrm{pg} / \mathrm{ml}) / 1000)^{-1.17} \times$ age $^{-0.13} \times 0.91[29]$.

Data collected previously as part of WDRS: Age at diagnosis and duration of type 1 diabetes (years from the date of diagnosis to the date of the ancillary study visit) were available from the WDRS. Within 3-4 months after diagnosis, once both the disease and management were more stable, a subgroup of the original WDRS participants provided a 24hour urine collection for C-peptide determination [30]. Participants followed detailed verbal and written instructions from study personnel, while following their usual diet and glucose management regimen. The 24-hour collection therefore captured an entire day's C-peptide secretion (thus reflecting the response to variable glucose levels), compared to a fasting or random level at a single point in time. The specifics of the collection and assay standards have been previously published [31]. The urine samples from 3-4 months after diagnosis were tested within 20 weeks of collection for urinary C-peptide levels as previously described [31].

At each WDRS follow-up visit, blood samples were obtained by venipuncture to determine total glycosylated hemoglobin $(\mathrm{GHb})$. Total $\mathrm{GHb}$ (which was the standard method to assess glycemic control during the early history of WDRS [30]) measures the total amount of hemoglobin in the blood that is glycosylated, compared with HbA1c (which is the current standard method to assess glycemic control) that evaluates only the glycosylation of a specific subtype of hemoglobin. As they both measure glycemic control, they are closely correlated ( $\mathrm{r}=0.98$, unpublished data from WDRS, January 2002) [23]. Patients were also asked to submit a blood sample from each visit with their primary care physician, or every four months if no visits were scheduled. Total GHb in the whole blood samples was measured within seven days of collection by Isolab GlycAffin microcolumn affinity chromatography (Isolab, Akron, $\mathrm{OH}$ ) as previously described [32].

These serial measurements of total GHb provided information on long-term glucose control. The longitudinal glucose control for each participant was calculated by averaging their total $\mathrm{GHb}$ measurements from the 10 years prior to the ancillary study. The number of total $\mathrm{GHb}$ measurements per participant ranged from one to 18 , with a mean of 7.8. One woman in the current analysis was missing a 10-year mean GHb.

Statistical analysis-Statistical analysis was performed using SAS, version 9.2 (SAS Institute, Cary, NC). The distribution of each variable was examined for normality, and skewed data were log transformed (e.g., TNF- $\alpha$ and C-peptide) or categorized if still skewed 
after log transformation (e.g., caffeine intake to quartiles). The dependent (outcome) variable was TNF-a level, and the independent variables included the information collected on Cpeptide at diagnosis, long-term glycemic control, diabetes duration, health behaviors and clinical factors. Data are presented as mean and standard deviation (SD) or median with interquartile range (IQR) for continuous variables, or as number and percent for categorical variables. Linear regression models were fitted to examine the unadjusted bivariate association of TNF-a levels with individual independent variables.

Multivariable regression models estimating TNF-a were built by individually entering each independent variable with $\mathrm{p}<0.10$ from the unadjusted bivariate analysis, and retaining those that were significant at $\mathrm{p}<0.05$ level. Two final multivariable models estimating TNF-a were built: one including the total sample of women ( $\mathrm{n}=87$; note 85 had complete data for the final model), and one in the subgroup of women with data on C-peptide levels at diagnosis $(n=50)$, as it was a significant predictor of TNF-a. The diabetes-related variables retained in the final models were assessed for collinearity, which was not found. The final models were then examined for confounding by all other independent variables, particularly those that might affect TNF-a such as age at diagnosis, BMI, waist-to-hip ratio (as measures of adiposity), glucose level at the time of blood draw, and vitamin D status; the regression coefficients for the significant independent variables remaining in the final models did not substantially change by $10 \%$ or more. Because of cytokine variability (e.g., with season [25] or timing within menses [24]), precision adjustment variables for TNF-a levels included the time intervals since rising and since last food intake, timing in the menstrual cycle, and calendar month of the blood draw [24,25]. Adjusting for these did not substantially change the regression coefficients in the final models, but were retained when statistically significant (e.g., season). As the two final models for TNF-a both included the 10-year mean $\mathrm{GHb}$, the models were further adjusted for the number of $\mathrm{GHb}$ measurements used to calculate the 10-year mean, to capture the varying precision of the estimates and possible health consciousness by the participant.

Effect modification (interaction) between the remaining significant independent variables was tested; the only significant interactions found were diabetes duration with both 10-year mean GHb and caffeine intake on TNF-a levels (details in results). To plot the interactions, duration of diabetes was stratified into two groups (above and below the mean of 16 years) and the levels of TNF- $a$ were calculated at mean values of the continuous independent variables and lowest levels (coded as 0 ) of the categorical independent variables in the final multivariable model.

\section{Results}

Characteristics of the 87 study participants with TNF-a levels determined are shown in Table 1 . The mean age was 27.9 years, and all but two were non-Hispanic white. The mean duration of diabetes was 16.0 years (range 13.2-18.4 years), with a mean current HbA1c of $8.1 \%(65 \mathrm{mmol} / \mathrm{mol})$. Nearly half $(43.7 \%)$ were using an insulin pump, with a median daily insulin requirement of approximately 0.7 units $/ \mathrm{kg}$. The mean eGFR was $48.8 \mathrm{~mL} / \mathrm{min} /$ $1.73 \mathrm{~m}^{2} ; 71.3 \%$ had an eGFR $<60 \mathrm{~mL} / \mathrm{min} / 1.73 \mathrm{~m}^{2}$. Overall, the characteristics of the 
subgroup of 50 women with C-peptide measured at diagnosis did not differ substantially from the characteristics of the total sample (Table 1).

In the final multivariable model including the total sample of women (Table $2 ; n=85$ with complete data), TNF-a levels were higher with longer duration of type 1 diabetes $(\mathrm{p}=0.0004)$ and worse current renal function as determined by lower eGFR levels $(\mathrm{p}=0.02)$. Further, diabetes duration significantly modified the associations of TNF-a levels with both mean glycemic control across the previous 10 years (10-year mean total $\mathrm{GHb}$; interaction $\mathrm{p}=0.01$ ) and current daily caffeine intake (interaction $\mathrm{p}=0.009$ ) (Table 2; Figure $2 \mathrm{~A} \& \mathrm{~B}$ ). To quantify the interactions, diabetes duration was categorized and remodeled (mean split: $\leq$ and $>16$ years). With a duration of disease $\leq 16$ years, the 10 -year mean GHb (\%) showed no association with TNF-a levels (log transformed $(\mathrm{pg} / \mathrm{ml}), \beta=-0.02$; Figure $2 \mathrm{~A}$, white diamonds), while at longer disease duration ( $>16$ years), there was a positive association with TNF-a levels ( $\beta=0.13$; black squares). For caffeine intake, at a disease duration $\leq 6$ years, daily caffeine intake (quartiles) had a positive association with TNF- $a$ levels ( $\beta=0.22$; Figure 2B, white diamonds), while at a disease duration longer than 16 years it had no association ( $\beta=0.02$; black squares). TNF- $\alpha$ levels were also negatively associated with years of education ( $\mathrm{p}=0.0009)$, and positively associated with the duration of fasting prior to blood being drawn $(\mathrm{p}=0.01)$ and spring/summer seasons $(\mathrm{p}<0.0001)$. TNF- $a$ levels were not associated with age at diagnosis, BMI, waist-to-hip ratio, insulin dose, blood glucose selfmonitoring, blood glucose at the time of blood draw, smoking, alcohol use, physical activity, or vitamin D levels. None of these factors were confounders of the significant associations with TNF-a.

In the subgroup of women with data on C-peptide levels at diagnosis $(n=50)$, current TNF- $\alpha$ levels at 13-18 years diabetes duration were independently associated with both the Cpeptide level at diagnosis and the mean total GHb over the most recent 10 years. TNF- $a$ levels had a significant inverse association with the level of C-peptide at diagnosis (both log transformed TNF- $\mathrm{a}(\mathrm{pg} / \mathrm{ml})$ and C-peptide (nmol/mmol-Cr), $\beta=-0.20, \mathrm{p}=0.01)$ - for each $1 \%$ decrement in C-peptide level at diagnosis there was a corresponding $0.2 \%$ increment in TNF-a level at 13-18 years duration (Figure 3). Controlling for age at study visit, age at diagnosis, BMI or waist-to-hip ratio did not change this association. In addition, TNF- $\alpha$ levels had a significant positive association with the 10 -year mean total $\mathrm{GHb}(\%, \beta=0.10$, $\mathrm{p}=0.01$ ). TNF-a levels were again significantly higher in blood drawn during spring or summer (compared with fall/winter, $\mathrm{p}=0.02$ ).

\section{Discussion}

In the present analysis of a population-based sample of young women with type 1 diabetes, levels of TNF- $a$ at prolonged diabetes durations were found to be associated with a variety of clinically relevant factors.

\section{TNF-a and C-peptide}

In the current analysis, a lower C-peptide level at the time of diagnosis of type 1 diabetes was associated with higher TNF-a levels 13-18 years later; this inverse association was independent of long-term glycemic control. Relatively few previous studies have looked at 
the relationship between TNF- $a$ and C-peptide levels - three cross-sectional studies found no association at diagnosis, or within three years of diagnosis $[6,10,14]$. The novel inverse association demonstrated in the current study suggests that lower C-peptide at diagnosis may lead to higher pro-inflammatory TNF-a levels over the long term, up to 13-18 years duration of type 1 diabetes. However, a lower level of C-peptide at the time of diagnosis may also be reflecting a more advanced autoimmune destruction of $\beta$-cells, possibly mediated in part by higher TNF-a levels that then persist over the long term. As this association is based on a single measurement of C-peptide, it will need confirmation in a larger cohort. It is important however to note that the mean C-peptide at diagnosis of $0.89 \mathrm{nmol} / \mathrm{mmol}-\mathrm{Cr}$ in our sample of women is consistent with C-peptide levels found in patients with type 1 diabetes within two years of diagnosis [33].

\section{TNF- $a$ and diabetes-related complications}

Higher TNF-a levels were found to be associated with lower current eGFR (i.e., worse renal function). Similarly, a cross-sectional analysis of the EURODIAB Study in type 1 diabetes [11] found that TNF-a levels were inversely associated with GFR, after adjustments similar to our final multivariable model including duration of disease and HbA1c. Further, they found that higher levels of TNF-a were associated with both more advanced stages of retinopathy and albuminuria, as well as the presence of cardiovascular disease. This is further supported by a longitudinal study, though in type 2 diabetes, that found baseline TNF-a levels were positively associated with progression of complications over one year [34]. In light of our data indicating that higher C-peptide may predict lower TNF-a levels years later, and data from the DCCT demonstrating that higher residual C-peptide levels were associated with lower incidence rates of microvascular complications [35], TNF- $a$ may be not only a marker for higher risk of complications, but may play a pathophysiological role in the progression of hypertension or microalbumiuria. A cross-sectional study that found a positive association between activation of the TNF-a system in type 1 diabetes and pulse pressure [36] supports this hypothesis. The analysis did not have concurrent data on other type 1 diabetes related complications such as hypertension, albuminuria or cardiovascular disease.

\section{TNF- $a$ and diabetes duration}

In looking at duration of disease above or below the mean of 16 years, we found TNF-a levels to be consistently higher in the group with longer duration of disease (Figure 2A \& B, black squares). Previous studies have found higher TNF-a levels in individuals newly diagnosed with type 1 diabetes compared to individuals with 1-3 years duration of disease $[6,8]$. In contrast, one prospective study of changes in TNF-a showed that levels did not change during the first 12 months after diagnosis [14], and a cross-sectional study found no difference in TNF-a levels in individuals with a duration of disease greater or less than five years [16]. In comparison, one prospective study found a trend towards increasing TNF- $a$ in the first two years after diagnosis [10]. Our finding of a higher level, at a notably longer duration of disease, extends these previous studies. Taken together, the data show fluctuations in TNF-a levels over the natural course of the disease from diagnosis to up to 18 years duration. Both the patient and the disease process itself may change over time, and TNF-a may be a reflection of different aspects of type 1 diabetes at different time points. 
Higher levels of TNF- $\alpha$ at diagnosis may be related to the islet cell antigen [5], while at longer duration it may be reflecting other facets of the disease such as glycemic control and complications.

\section{TNF- $a$ and glycemic control}

In the current study, the association of long-term glycemic control, as measured by the mean total GHb over the previous 10 years, with TNF-a levels was significantly modified by the duration of type 1 diabetes: a positive association was found between the 10-year mean $\mathrm{GHb}$ and TNF-a level with a longer duration of disease (specifically greater than the mean of 16 years), while there was no association for those with a shorter duration of disease. One previous cross-sectional study in type 1 diabetes found a positive correlation between TNF- $\mathrm{a}$ and $\mathrm{HbAlc} \mathrm{[16],} \mathrm{whereas} \mathrm{several} \mathrm{have} \mathrm{found} \mathrm{no} \mathrm{association} \mathrm{[6,10];} \mathrm{these} \mathrm{studies} \mathrm{did} \mathrm{not}$ have as extensive of a follow-up period, nor did they utilize such a long-term measure of glycemic control. Research in individuals with impaired glucose tolerance demonstrated that clamp-induced hyperglycemia acutely increased the levels of pro-inflammatory cytokines, including TNF-a [15], and the increase in levels persisted longer compared to controls.

Taken together, these data indicate that glucose can not only acutely induce higher levels of TNF-a, but may also help maintain higher TNF-a levels in individuals with abnormal glucose metabolism, perhaps most particularly in those with type 1 diabetes of longer duration.

\section{TNF- $a$ and caffeine}

The association of daily caffeine consumption with TNF-a levels was also significantly modified by the duration of disease: a positive association was found between daily caffeine consumption and TNF-a level with a shorter duration of disease (specifically less than the mean of 16 years), while there was no association in those with a longer duration of disease. In one study of healthy men and women, a positive association was found between daily coffee consumption and TNF-a levels [37], even after adjustment for demographics, diet, and clinical factors. Conversely, in several in vitro studies, caffeine has been found to suppress TNF-a secretion [38,39]. To the best of our knowledge, this is a novel finding in type 1 diabetes. As higher TNF-a levels may be associated with both micro- and macrovascular complications in type 1 diabetes [11], educating patients to consume less caffeine may have a beneficial effect on inflammatory cytokine levels.

\section{Strengths and limitations}

This study is novel in that it examined young women from a population-based Registry of incident type 1 diabetes, with extensive length of follow-up and longitudinal data available. This provided an opportunity to examine the prospective associations of TNF-a levels at prolonged diabetes durations with C-peptide at diagnosis, diabetes duration, and previous long-term glycemic control, where such associations may not be apparent at shorter durations of disease. In addition, health behaviors and clinical factors were included for analysis and to adjust for potential confounding if needed. Another strength of this study is since it included many measurements of health status, examination of multiple associations was performed. The risk of Type 1 error is likely low, as in the final model, all but one of the p-values is $\leq 0.01$. 
The study does have some limitations, notably it included almost exclusively white women, so findings may be different in males and other racial/ethnic groups. While the diagnosis of type 1 diabetes was made on a clinical basis, only seven participants in the entire WDRS discontinued insulin therapy after enrollment, and with more than 20 years of follow-up now to date, this supports the accuracy of the initial diagnosis. While total glycosylated hemoglobin and 24-hour urinary C-peptide may not be in common use today, they were the tests in use at the time of initial data collection and were valid measures of glucose control and C-peptide secretion, respectively. As such, the direction and statistical significance of the associations of TNF-a with glycemic control and residual C-peptide detected still hold, however the clinical interpretation of the regression coefficients will not be directly relatable to current $\mathrm{HbA} 1 \mathrm{c}$ and $\mathrm{C}$-peptide measures. As many factors were controlled for in the data collection process and because the population was quite homogeneous, thus resulting in high internal validity, the study results will need replication, in particular with regard to Cpeptide, in more diverse samples. Similar to the majority of prior studies on TNF- $a$ in type 1 diabetes $[6,8,11,12,16]$, there was a single measurement of TNF-a, limiting prospective evaluation of changes in levels on outcomes. However studies in other chronic diseases have shown a single TNF-a level to be predictive of poor outcomes and/or mortality [40,41].

\section{Conclusions}

In summary, this study provides a unique longitudinal assessment of TNF-a at longer durations of type 1 diabetes. Interestingly, lower C-peptide levels at diagnosis independently predicted a higher pro-inflammatory TNF-a level years later. This association needs confirmation in a larger study. In addition, poor glycemic control over the previous 10 years predicted higher TNF-a levels, specifically in those with a longer duration of disease. Also, consistent with prior research in type 1 diabetes, higher inflammatory TNF-a levels were associated with worse renal function. Given the recognized associations between TNF-a and complications in type 1 diabetes, further studies using longitudinal evaluation of multiple cytokines may help clarify the associations, which are likely complex, between glycemic control, inflammation, and the progression of diabetes-related complications.

\section{Acknowledgments}

This publication was made possible by Grant Number 1-05-CR-35 from the American Diabetes Association; Grant Number K12HD055892 from the National Institute of Child Health and Human Development (NICHD) and the National Institutes of Health Office of Research on Women's Health (ORWH); Grant Number R01DK036904 from the National Institute of Diabetes and Digestive and Kidney Diseases (NIDDK); and Grant Number UL1RR029879 from the National Institutes of Health National Center for Research Resources.

\section{References}

1. Nathan DM, Cleary PA, Backlund JY, Genuth SM, Lachin JM, Orchard TJ, et al. The Diabetes Control and Complications Trial/Epidemiology of Diabetes Interventions Study Research Group. Intensive diabetes treatment and cardiovascular disease in patients with type 1 diabetes. $\mathrm{N}$ Engl J Med. 2005; 353:2643-2653. [PubMed: 16371630]

2. Bell RA, Mayer-Davis EJ, Beyer JW, D'Agostino RB Jr, Lawrence JM, Linder B, et al. The SEARCH for Diabetes in Youth Study Group. Diabetes in non-hispanic white youth: Prevalence, incidence, and clinical characteristics. Diabetes Care. 2009; 32(Suppl 2):S102-111. [PubMed: 19246575] 
3. Pettitt DJ, Talton J, Dabelea D, Divers J, Imperatore G, Lawrence JM, et al. Prevalence of diabetes in U.S. youth in 2009: The SEARCH for Diabetes in Youth Study. Diabetes Care. 2014; 37:402408. [PubMed: 24041677]

4. Rabinovitch A, Suarez-Pinzon WL. Roles of cytokines in the pathogenesis and therapy of type 1 diabetes. Cell Biochem Biophys. 2007; 48:159-163. [PubMed: 17709885]

5. Padgett LE, Broniowska KA, Hansen PA, Corbett JA, Tse HM. The role of reactive oxygen species and proinflammatory cytokines in type 1 diabetes pathogenesis. Ann N Y Acad Sci. 2013; 1281:1635. [PubMed: 23323860]

6. Ozer G, Teker Z, Cetiner S, Yilmaz M, Topaloglu AK, Onenli-Mungan N, et al. Serum IL-1, IL-2, TNFalpha and INFgamma levels of patients with type 1 diabetes mellitus and their siblings. J Pediatr Endocrinol Metab. 2003; 16:203-210. [PubMed: 12713258]

7. Kaas A, Pfleger C, Kharagjitsingh AV, Schloot NC, Hansen L, Buschard K, et al. The Hvidoere Study Group on Childhood Diabetes. Association between age, IL-10, IFNgamma, stimulated Cpeptide and disease progression in children with newly diagnosed type 1 diabetes. Diabet Med. 2012; 29:734-741. [PubMed: 22150609]

8. Erbagci AB, Tarakcioglu M, Coskun Y, Sivasli E, Sibel Namiduru E. Mediators of inflammation in children with type I diabetes mellitus: cytokines in type I diabetic children. Clin Biochem. 2001; 34:645-650. [PubMed: 11849625]

9. Basu S, Larsson A, Vessby J, Vessby B, Berne C. Type 1 diabetes is associated with increased cyclooxygenase- and cytokine-mediated inflammation. Diabetes Care. 2005; 28:1371-1375. [PubMed: 15920054]

10. Espersen GT, Mathiesen O, Grunnet N, Jensen S, Ditzel J. Cytokine plasma levels and lymphocyte subsets in patients with newly diagnosed insulin-dependent (type 1) diabetes mellitus before and following initial insulin treatment. APMIS. 1993; 101:703-706. [PubMed: 8240789]

11. Schram MT, Chaturvedi N, Schalkwijk CG, Fuller JH, Stehouwer CD. Eurodiab Prospective Complications Study Group. Markers of inflammation are cross-sectionally associated with microvascular complications and cardiovascular disease in type 1 diabetes--the EURODIAB Prospective Complications Study. Diabetologia. 2005; 48:370-378. [PubMed: 15692810]

12. Zorena K, Kula M, Malinowska E, Raczynska D, Mysliwiec M, Raczynska K. Threshold serum concentrations of tumour necrosis factor alpha (TNF alpha) as a potential marker of the presence of microangiopathy in children and adolescents with type 1 diabetes mellitus (T1DM). Hum Immunol. 2013; 74:75-81. [PubMed: 23073299]

13. Machnica L, Deja G, Polanska J, Jarosz-Chobot P. Blood pressure disturbances and endothelial dysfunction markers in children and adolescents with type 1 diabetes. Atherosclerosis. 2014; 237:129-134. [PubMed: 25238220]

14. Pfleger C, Mortensen HB, Hansen L, Herder C, Roep BO, Hoey H, et al. Hvidore Study Group on Childhood Diabetes. Association of IL-1ra and adiponectin with C-peptide and remission in patients with type 1 diabetes. Diabetes. 2008; 57:929-937. [PubMed: 18299313]

15. Esposito K, Nappo F, Marfella R, Giugliano G, Giugliano F, Ciotola M, et al. Inflammatory cytokine concentrations are acutely increased by hyperglycemia in humans: role of oxidative stress. Circulation. 2002; 106:2067-2072. [PubMed: 12379575]

16. Lechleitner M, Koch T, Herold M, Dzien A, Hoppichler F. Tumor necrosis factor-alpha plasma level in patients with type 1 diabetes mellitus and its association with glycemic control and cardiovascular risk factors. J Intern Med. 2000; 248:67-76. [PubMed: 10947883]

17. Targher G, Zenari L, Bertolini L, Muggeo M, Zoppini G. Elevated levels of interleukin-6 in young adults with type 1 diabetes without clinical evidence of microvascular and macrovascular complications. Diabetes Care. 2001; 24:956-957. [PubMed: 11347765]

18. Reis JS, Amaral CA, Volpe CM, Fernandes JS, Borges EA, Isoni CA, et al. Oxidative stress and interleukin- 6 secretion during the progression of type 1 diabetes. Arq Bras Endocrinol Metabol. 2012; 56:441-448. [PubMed: 23108749]

19. Snell-Bergeon JK, West NA, Mayer-Davis EJ, Liese AD, Marcovina SM, D'Agostino RB Jr, et al. Inflammatory markers are increased in youth with type 1 diabetes: The SEARCH Case-Control study. J Clin Endocrinol Metabol. 2010; 95:2868-2876. 
20. Palta M, LeCaire T, Daniels K, Shen G, Allen C, D'Alessio D. Risk factors for hospitalization in a cohort with type 1 diabetes. Wisconsin Diabetes Registry. Am J Epidemiol. 1997; 146:627-636. [PubMed: 9345116]

21. Diabetes mellitus. Report of a WHO Study Group. World Health Organ Tech Rep Ser. 1985; 727:1-113. [PubMed: 3934850]

22. Report of the expert committee on the diagnosis and classification of diabetes mellitus. Diabetes Care. 1997; 20:1183-1197. [PubMed: 9203460]

23. Danielson KK, Elliott ME, LeCaire T, Binkley N, Palta M. Poor glycemic control is associated with low BMD detected in premenopausal women with type 1 diabetes. Osteoporos Int. 2009; 20:923-933. [PubMed: 18830554]

24. Konecna L, Yan MS, Miller LE, Scholmerich J, Falk W, Straub RH. Modulation of IL-6 production during the menstrual cycle in vivo and in vitro. Brain, Behav Immun. 2000; 14:49-61. [PubMed: 10729217]

25. Svensson J, Eising S, Hougaard DM, Mortensen HB, Skogstrand K, Simonsen LB, et al. Few differences in cytokines between patients newly diagnosed with type 1 diabetes and their healthy siblings. Hum Immunol. 2012; 73:1116-1126. [PubMed: 22906888]

26. Willett WC, Sampson L, Stampfer MJ, Rosner B, Bain C, Witschi J, et al. Reproducibility and validity of a semiquantitative food frequency questionnaire. Am J Epidemiol. 1985; 122:51-65. [PubMed: 4014201]

27. Sallis JF, Haskell WL, Wood PD, Fortmann SP, Rogers T, Blair SN, et al. Physical activity assessment methodology in the five-city project. Am J Epidemiol. 1985; 121:91-106. [PubMed: 3964995]

28. The effect of intensive treatment of diabetes on the development and progression of long-term complications in insulin-dependent diabetes mellitus. The Diabetes Control and Complications Trial Research Group. N Engl J Med. 1993; 329:977-986. [PubMed: 8366922]

29. Stevens LA, Coresh J, Schmid CH, Feldman HI, Froissart M, Kusek J, et al. Estimating GFR using serum cystatin $\mathrm{C}$ alone and in combination with serum creatinine: a pooled analysis of 3,418 individuals with CKD. Am J Kidney Dis. 2008; 51:395-406. [PubMed: 18295055]

30. Palta M, Shen G, Allen C, Klein R, D'Alessio D. Longitudinal patterns of glycemic control and diabetes care from diagnosis in a population-based cohort with type 1 diabetes. The Wisconsin Diabetes Registry. Am J Epidemiol. 1996; 144:954-961. [PubMed: 8916506]

31. Allen C, Zaccaro DJ, Palta M, Klein R, Duck SC, D'Alessio DJ. Glycemic control in early IDDM. The Wisconsin Diabetes Registry. Diabetes Care. 1992; 15:980-987. [PubMed: 1505330]

32. Duck SC, Lee M, D'Alessio D. 24-42 month stability of internal blood standards for glycated hemoglobin analysis. Diabetes Res Clin Pract. 1990; 9:195-199. [PubMed: 2376239]

33. Gjessing HJ, Matzen LE, Faber OK, Froland A. Fasting plasma C-peptide, glucagon stimulated plasma C-peptide, and urinary C-peptide in relation to clinical type of diabetes. Diabetologia. 1989; 32:305-311. [PubMed: 2666217]

34. Preciado-Puga MC, Malacara JM, Fajardo-Araujo ME, Wrobel K, Wrobel K, Kornhauser-Araujo $\mathrm{C}$, et al. Markers of the progression of complications in patients with type 2 diabetes: a one-year longitudinal study. Exp Clin Endocrinol Diabetes. 2014; 122:484-490. [PubMed: 25230243]

35. Steffes MW, Sibley S, Jackson M, Thomas W. Beta-cell function and the development of diabetesrelated complications in the diabetes control and complications trial. Diabetes Care. 2003; 26:832836. [PubMed: 12610045]

36. Gonzalez-Clemente JM, Gimenez-Perez G, Richart C, Broch M, Caixas A, Megia A, et al. The tumour necrosis factor (TNF)-alpha system is activated in accordance with pulse pressure in normotensive subjects with type 1 diabetes mellitus. Eur J Endocrinol. 2005; 153:687-691. [PubMed: 16260427]

37. Zampelas A, Panagiotakos DB, Pitsavos C, Chrysohoou C, Stefanadis C. Associations between coffee consumption and inflammatory markers in healthy persons: the ATTICA study. Am J Clin Nutr. 2004; 80:862-867. [PubMed: 15447891]

38. Horrigan LA, Kelly JP, Connor TJ. Caffeine suppresses TNF-a lpha production via activation of the cyclic AMP/protein kinase A pathway. Int Immunopharmacol. 2004; 4:1409-1417. [PubMed: 15313438] 
39. van Furth AM, Seijmonsbergen EM, Langermans JA, van der Meide PH, van Furth R. Effect of xanthine derivates and dexamethasone on Streptococcus pneumoniae-stimulated production of tumor necrosis factor alpha, interleukin-1 beta (IL-1 beta), and IL-10 by human leukocytes. Clin Diagn Lab Immunol. 1995; 2:689-692. [PubMed: 8574830]

40. Deswal A, Petersen NJ, Feldman AM, Young JB, White BG, Mann DL. Cytokines and cytokine receptors in advanced heart failure: an analysis of the cytokine database from the Vesnarinone trial (VEST). Circulation. 2001; 103:2055-2059. [PubMed: 11319194]

41. Rordorf R, Savastano S, Sanzo A, Spazzolini C, De Amici M, Camporotondo R, et al. Tumor necrosis factor-alpha predicts response to cardiac resynchronization therapy in patients with chronic heart failure. Circ J. 2014; 78:2232-2239. [PubMed: 24954238] 
Sample

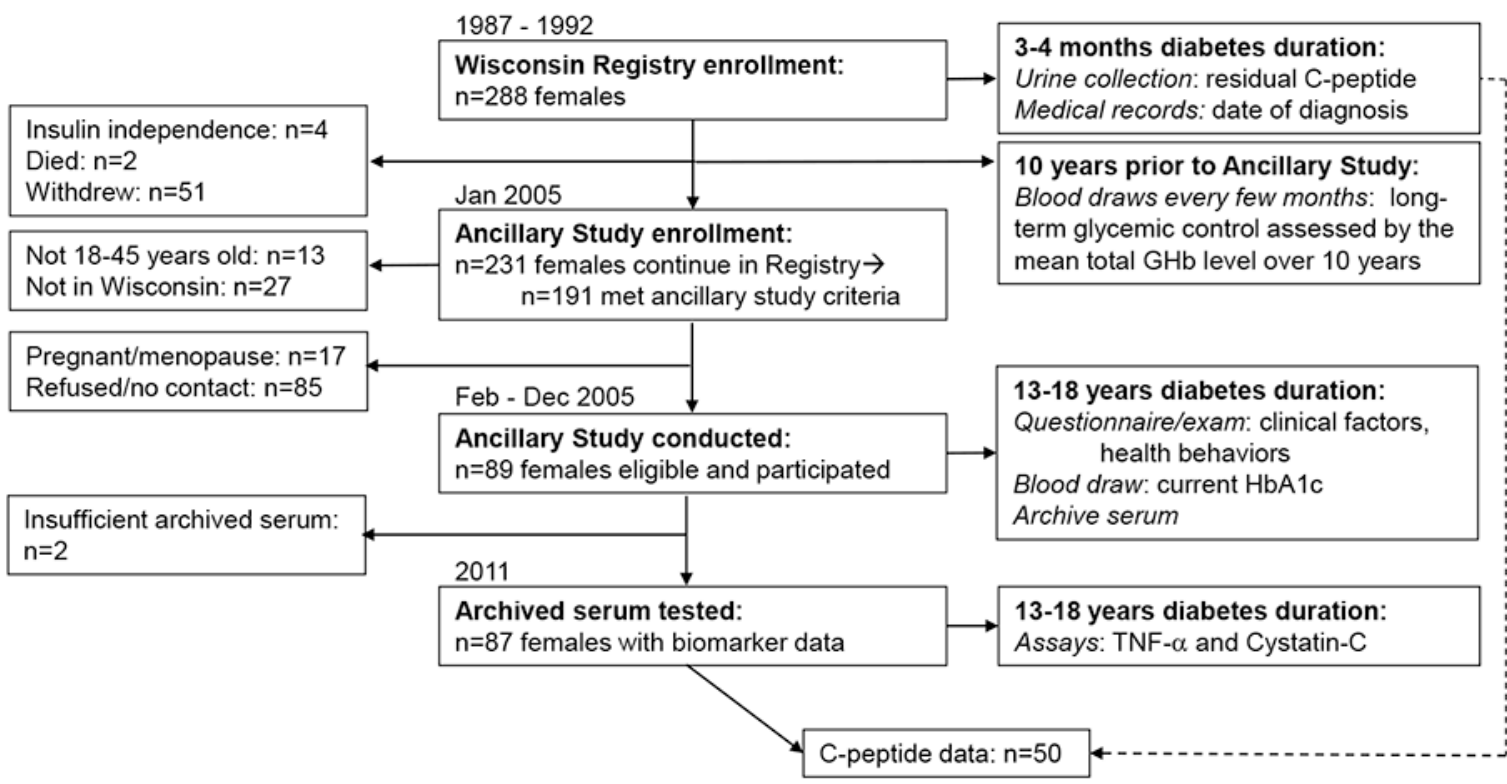

Figure 1.

Diagram of participants enrolled from the Wisconsin Diabetes Registry Study into the ancillary study of young women at 13-18 years type 1 diabetes duration, along with the timeline and data collected. 
A

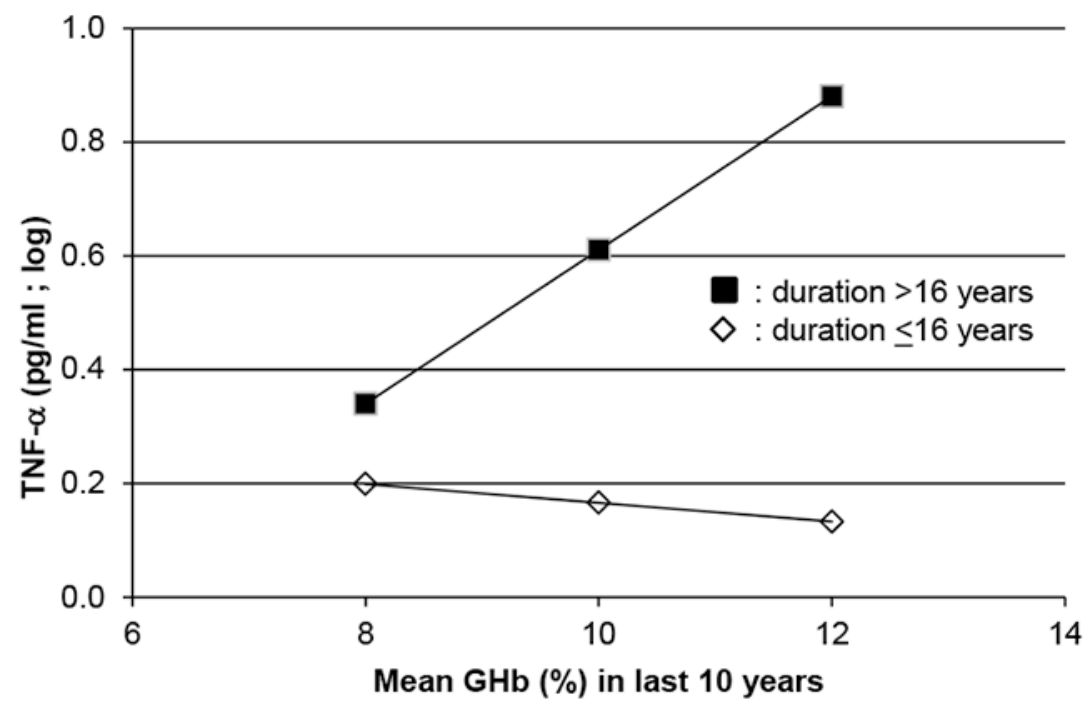

B

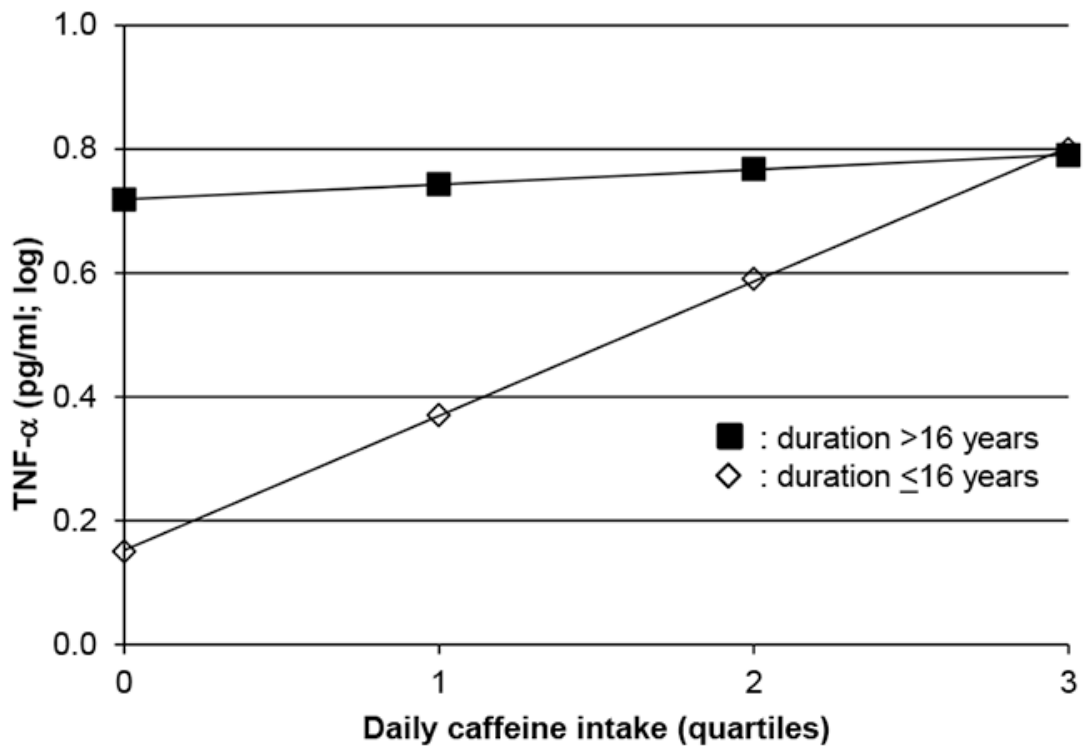

Figure 2.

Plots of the associations with TNF-a levels at 13-18 years duration, modified by type 1 diabetes duration.

White diamonds: duration of type 1 diabetes $\leq$ the mean of 16 years.

Black squares: duration of type 1 diabetes $>$ the mean of 16 years.

A. Plot of the positive association between 10-year mean total GHb and TNF-a at durations of type 1 diabetes above the mean, with no association at shorter durations. Estimates plotted using final multivariable model in Table 2, centered at mean eGFR, years of education, and time fasting prior to blood draw, with blood drawn in fall/winter, at lowest quartile of caffeine intake.

B. Plot of the positive association between daily caffeine intake and TNF-a at durations of type 1 diabetes below the mean, with no association at longer durations. Estimates plotted using final multivariable model in Table 2, centered at mean eGFR, 10-year mean GHb, 
years of education, and time fasting prior to blood draw, with blood drawn in fall/winter. See Table 1 for quartiles of caffeine intake. 


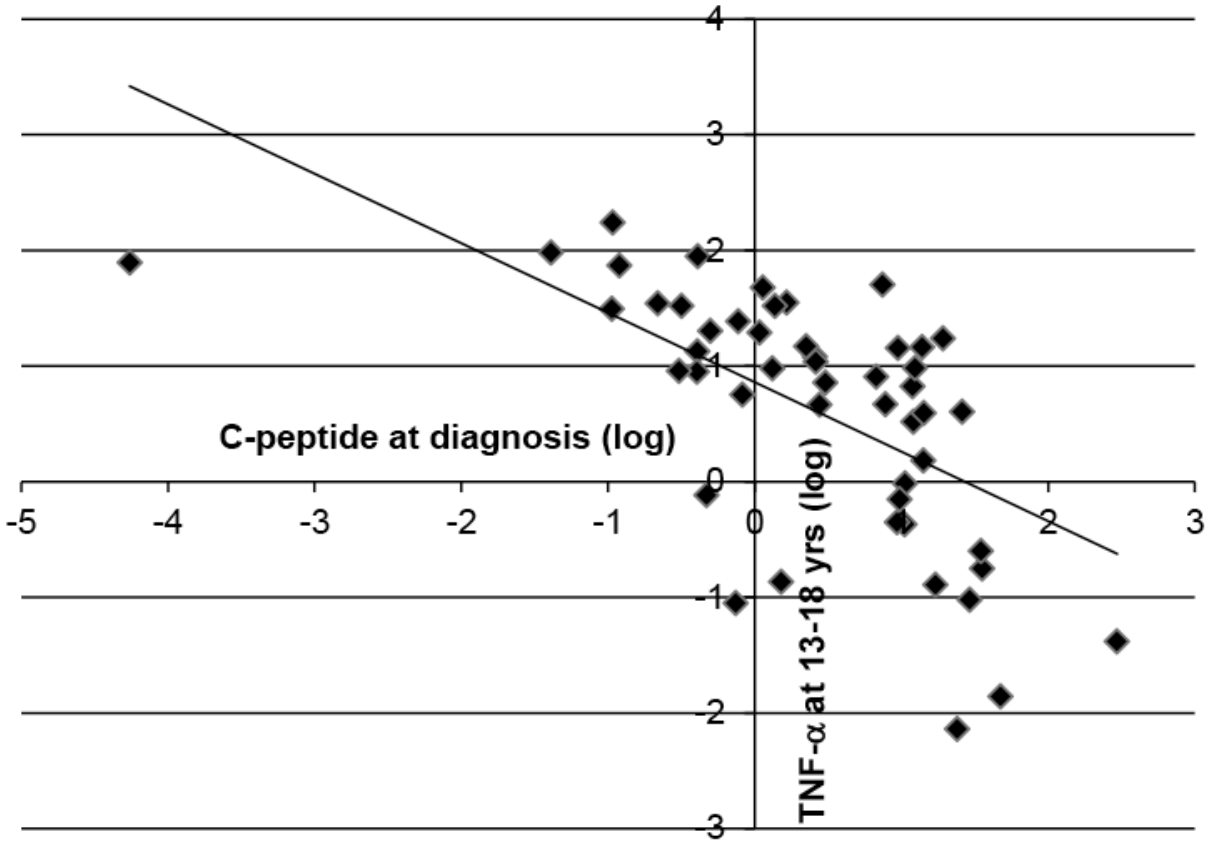

Figure 3.

Scatter plot of the negative association between C-peptide $(\log )$ at diagnosis and TNF-a levels $(\log )$ at 13-18 years after diagnosis of type 1 diabetes. 


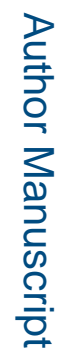

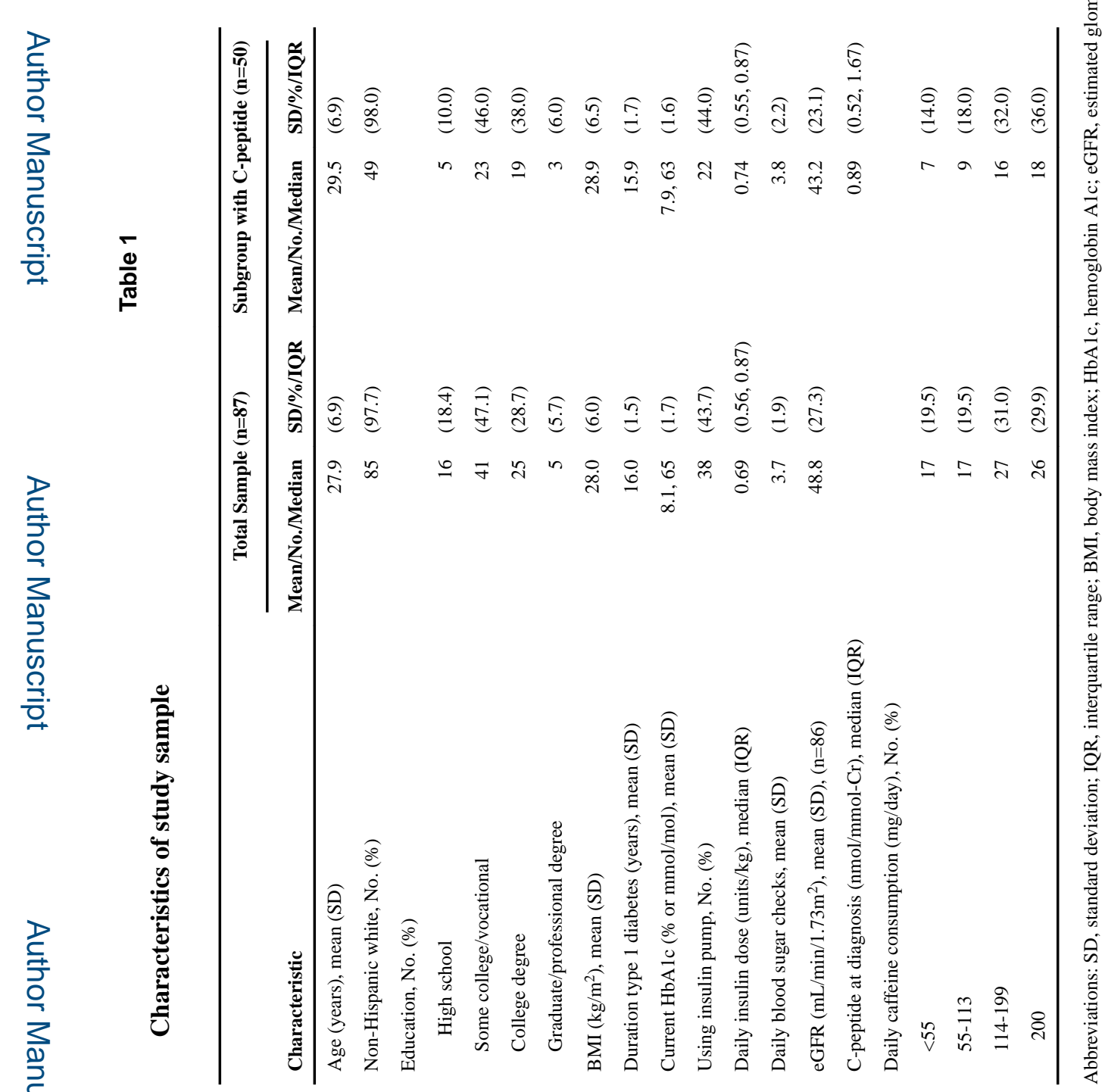

Exp Clin Endocrinol Diabetes. Author manuscript; available in PMC 2017 March 23. 
Table 2

Final multivariable model estimating TNF-a levels $(\log )$ at 13-18 years diabetes duration in the total group of women $(\mathbf{n}=85)$

\begin{tabular}{lll}
\hline Variable & $\beta$ & p-value \\
\hline Duration of diabetes (years) & 0.29 & 0.0004 \\
eGFR $\left(\mathrm{mL} / \mathrm{min} / 1.73 \mathrm{~m}^{2}\right)$ & -0.01 & 0.02 \\
10-year mean total GHb $(\%)$ & 0.07 & 0.009 \\
$\quad$ Interaction: Duration * 10-year mean total GHb & 0.05 & 0.01 \\
Daily caffeine intake (quartiles of mg/day; see Table 1) & 0.13 & 0.01 \\
$\quad$ Interaction: Duration * Daily caffeine intake & -0.10 & 0.009 \\
Education (years) & -0.07 & 0.0009 \\
Time fasting prior to blood draw (hours; log) & 0.16 & 0.01 \\
Season (ref=fall/winter) & & $<0.0001^{a}$ \\
$\quad$ Spring & 0.76 & $<0.0001$ \\
Summer & 0.60 & $<0.0001$ \\
\hline
\end{tabular}

Abbreviations: eGFR, estimated glomerular filtration rate; GHb, glycosylated hemoglobin.

Variables centered at mean include: GHb (mean 10.8) and duration of diabetes (mean 16.0) for interpretability of interactions. $\mathrm{n}=1$ missing 10 -year mean total GHb, $\mathrm{n}=1$ Cystatin-C/eGFR outlier removed.

Adjusted for number of total GHb measurements used to calculate 10-year mean.

${ }^{a}$ Overall p-value. 